Proceedings of the 2011 Winter Simulation Conference

S. Jain, R.R. Creasey, J. Himmelspach, K.P. White, and M. Fu, eds.

\title{
A MULTICRITERIA SIMULATION OPTIMIZATION METHOD FOR INJECTION MOLDING
}

\author{
María G. Villarreal-Marroquín \\ José M. Castro \\ The Ohio State University \\ 1971 Neil Ave., Room 210 \\ Columbus, OH 43210, USA
}

\author{
Mauricio Cabrera-Ríos \\ University of Puerto Rico at Mayagüez \\ PO Box 9000 \\ Mayagüez, PR 00681, USA
}

\begin{abstract}
Injection Molding is one of the most important processes for mass-producing plastic products. To help improve and facilitate the molding of plastic parts, advanced computer simulation tools have been developed. While modeling is complicated by itself, the difficulty of optimizing the injection molding process is that its performance measures usually show conflicting behaviors. Therefore, the best solution for one performance measure is usually not the best for other performance measures. This paper introduces a simulation optimization method that considers multiple performance measures and is able to find a set of efficient solutions without having to evaluate a large number of simulations. The main components of the method are metamodeling and design of experiments. The method is illustrated and detailed here using a simple test example. Furthermore, it is applied to a real injection molding case. The performance of the method using different design of experiments is also discussed.
\end{abstract}

\section{INTRODUCTION}

Polymers have been increasingly replacing metallic components in many applications such as the manufacture of automobiles, aircrafts, toys, appliances, office equipment, among others. This is because they are very versatile materials. Nowadays, many consumer products such as computer and automobile components rely on the technology and production of polymer companies. Thus, it is important to design reliable processes to ensure low cost and high quality products.

In Injection Molding (IM), for instance, processing conditions such as melt temperature, mold temperature, pack/hold pressure and duration, and cooling time have to be properly set to ensure the quality of the molded components. Often, these conditions are set by process engineers based on prior experience, resin supplier's recommendations, and/or reference handbooks. These conditions are usually further adjusted by trial and error on the shop floor. This approach is highly dependent on the experience of molding operators and can be costly and time consuming, especially with new resins and/or new applications (Zhou and Turng 2007). However, with recent advances in numerical modeling and computer simulation techniques, a large effort has been made in developing computer simulation tools to help improve and facilitate the modeling of plastic parts.

The use of simulation for selecting injection molding processing conditions has been the subject of much research in the past (Smith, Tortorelli, and Tucker 1998; Alam and Kamal 2005). Specialists usually generate a limited number of solutions from which one is finally selected. Nevertheless, this does not guarantee having found the optimal solution. Therefore, there is a lot of potential to be exploited in the adequate and efficient selection of optimization techniques for the design of manufacturing processes through computer simulations. Such potential explains the relatively recent and rapidly increasing interest in Simulation Optimization (SO) or Optimization via Simulation (OvS) as a field on its own. The objective of a SO method is to provide a structure to determine the values of the controllable variables that op- 


\section{Villarreal-Marroquín, Cabrera-Ríos, and Castro}

timize an objective function defined as a combination of the simulation model's outputs (performance measures) (Swisher et al. 2000). An optimization routine uses the calculated values of the objective function along with previous evaluations to select a new set of input values; this is continued until a preselected convergence criterion is satisfied (April et al. 2004).

Contributions in the area of OvS have primarily focused on discrete-event simulations and not on continuous or physics-based simulations like the ones used to model polymer processes. One reason is that the computational time required to run physics-based simulation models is usually very long. Consequently, having an iterative algorithm that requires many simulation runs to find the processing conditions to optimize different performance measures simultaneously is not computationally practical. As a result, metamodeling-based techniques (Simpson et al. 2001) have played an important role on the analysis of physics-based simulation models. Metamodels are mathematical representations of real phenomena based on a limited number of measurements. These measurements can take the form of the outputs of a simulation model, overcoming the need to run the simulation many times. The evaluation time of a metamodel is considered to be much shorter than that of the simulation software. In such cases, new solutions can be estimated rather inexpensively.

Common SO methodologies are mainly characterized by the use of one objective function representing a performance measure (PM), as the one our group presented earlier at the Winter Simulation Conference (Villarreal et al. 2008). However, in injection molding, we are typically interested in optimizing a set of performance measures as opposed to a single one. And, as previously mentioned, the controllable variables in general have conflicting effects on the performance measures. Therefore the best solution for one performance measure is usually not the best for some other performance measure. Thus it is not the best approach to obtain a single solution but rather a set of solutions corresponding to the best compromises (efficient solutions). The efficient solutions are the solutions for which none of the performance measures can be improved without deteriorating another. This last task falls into the emerging area of Optimization via Simulation with Multiple Performance Measures.

Recent contributions to the area of multicriteria optimization via simulation that used metamodeling are those of Dellino and Kleijnen (2009) and Zakerifar, Biles, and Evens (2009). Both works used Response Surface Methodology and Kriging metamodels to represent multiple PMs in inventory problems. Ryu, Kim, and Wan (2009) used quadratic metamodels to characterize the PMs of a variety of multicriteria simulation optimization problems, that is, problems with different forms of efficient frontier.

This manuscript presents a multicriteria optimization via simulation method which integrates design of experiments and metamodeling techniques to reduce the number of simulation runs needed to solve the multicriteria problem. The method is first introduced in section 2 and illustrated with a simple test case in section 3. Finally, in section 4, it is applied to a real injection molding case.

\section{PROPOSED METHOD}

In a previous work (Villarreal et al. 2008) our group introduced a single objective optimization via simulation method whose objective was to find the best process conditions using a small number of simulation runs. The algorithm was tested using different global optimization test functions with satisfactory results. It was also tested using several small discrete event simulations as well as continuous simulation models. The method was applied to the simulation of an actual painting line operation, as well as several injection molding parts, such as an automobile bumper and a disposable camera. While the optimization algorithm was designed to solve single criteria optimization problems it was used to solve some multicriteria problems by combining different performance measures into a single objective function. Here, the method is extended to solve multicriteria optimization via simulation problems without the need to define a single objective function. The current method is similar to the previous approach in that it combines design of experiments and metamodeling techniques to reduce the number of simulation run required to obtain the best processing condition to minimize (maximize) a set of performance measures.

The Multicriteria Optimization via Simulation methodology proposed here is schematically shown in Figure 1. The method starts with an experimental design (DOE) from which a simulation run is performed 
at each design point. Then, the set of best compromises between all performance measures is set as the incumbent efficient frontier. At each iteration, a metamodel for each PM is constructed using all the available information. Then, through these metamodels, feasible solutions are generated and a predicted efficient frontier is found. The predicted efficient solutions are then simulated and compared against the incumbent efficient solutions for updating purposes. A series of stopping criteria are evaluated and, if none is met, the new points are added to the existing set of points and a new iteration begins. Otherwise, the method stops and the incumbent efficient frontier is reported.

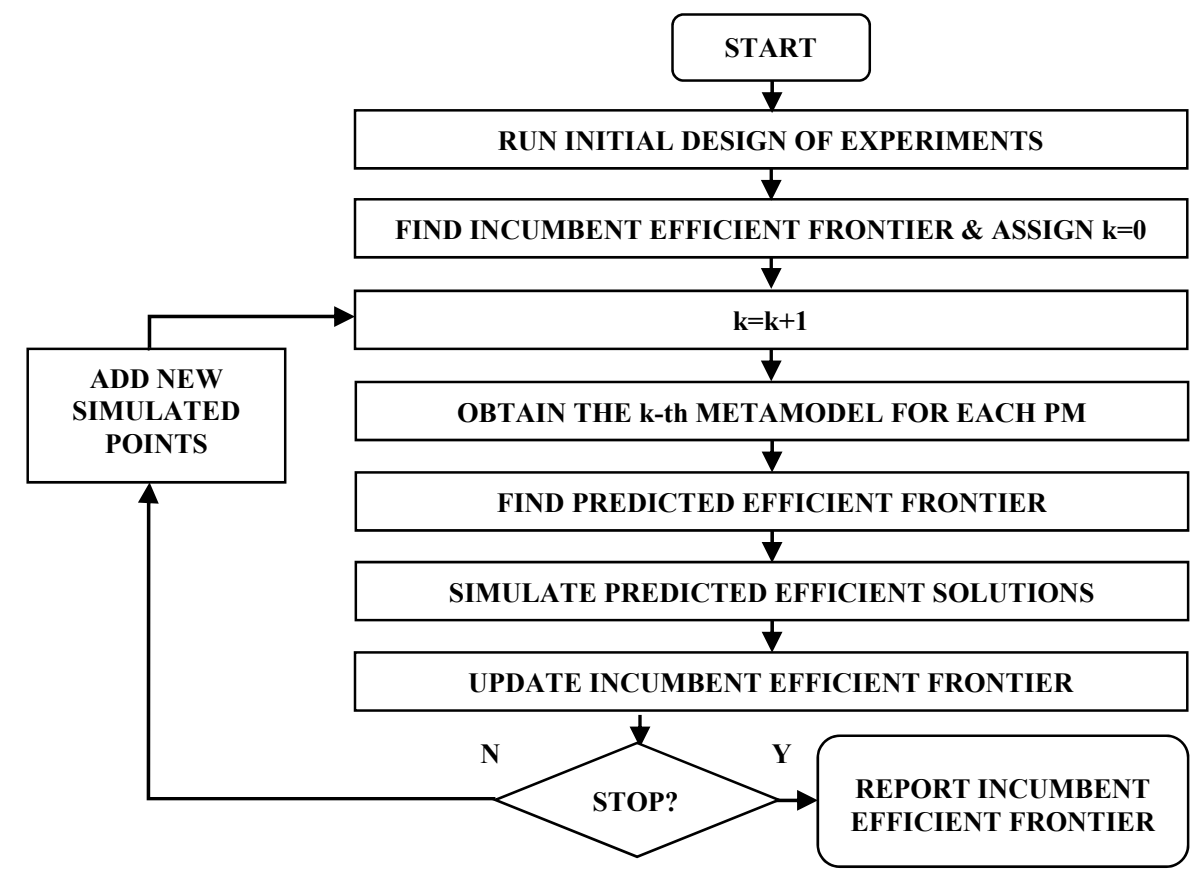

Figure 1: Sketch of proposed Multicriteria Optimization via Simulation algorithm.

The decision to use design of experiments and metamodels to represent the outputs of the simulation model to reduce computational time follows from the large number of works related to simulation-based metamodels (Azadivar 1999; Swisher et al. 2000; Fu 2001; Ólafsson and Kim 2002; Fu, Glover, and April 2005), as well as previous work of our research group on the optimization of physical and chemical polymer processing phenomena (Cabrera-Ríos, Castro, and Mount-Campbell 2002; Cabrera-Ríos et al. 2002; Castro et al. 2005, 2007; Villarreal et al. 2008).

There are several methods to approach multicriteria optimization problems such as simulated annealing and evolutionary algorithms; here Data Envelopment Analysis (DEA) (Charnes et al. 1993) is used. DEA has been previously used in our research group to solve multicriteria optimization problems in manufacturing (Cabrera-Ríos, Castro, and Mount-Campbell 2002). The main motivations for using DEA to solve the multiple criteria optimization problems are: (1) DEA uses linear programming, which is the simplest optimization problem, (2) DEA can be carried out using easily available software, like MS Excel, and (3) once an efficient solution is identified by DEA, one can be sure that it is indeed an efficient solution.

The next section illustrates and details of the proposed multicriteria simulation optimization methodology using two global optimization test functions as performance measures.

\section{ILLUSTRATION OF PROPOSED METHOD}

In order to illustrate and detail the proposed methodology, two known global optimization test functions were used. The test functions are assumed to be the output of the simulation model. The test functions 
used are the Rastrigin's function $\left(f_{1}\left(x_{1}, x_{2}\right)=20+x_{1}{ }^{2}+x_{2}{ }^{2}-10\left(\cos 2 \pi x_{1}+\cos 2 \pi x_{2}\right)\right)$, and the Six-hump camel back function $\left(f_{2}\left(x_{1}, x_{2}\right)=\left(4-2.1 x_{1}^{2}+x_{1}^{4} / 3\right) x_{1}^{2}+x_{1} x_{2}+\left(-4+4 x_{2}^{2}\right) x_{2}^{2}\right)$. The first function is to be minimized and the second to be maximized. Two inputs (controllable variables) were chosen, $x_{1}$ and $x_{2}$, both with lower and upper limit of -1 and 1 respectively. The optimal solution(s) for each function are given in Table 1. From Table 1 one can see that the optimal solution for the Rastrigin's function $\left(f_{1}\right)$ does not correspond to the optimal solution of the Six-hump camel back function $\left(f_{2}\right)$, implying a conflict between them.

Figure 2 shows the values of both functions for a set of 10,000 random values of $x_{1}$ and $x_{2}$ on the experimental region. An ideal (utopia) solution in this case will be on the North-West corner of the plot, but there is not a solution there. Then we need to identify the set of best compromises. The efficient solutions for this case are given in Table 2 .

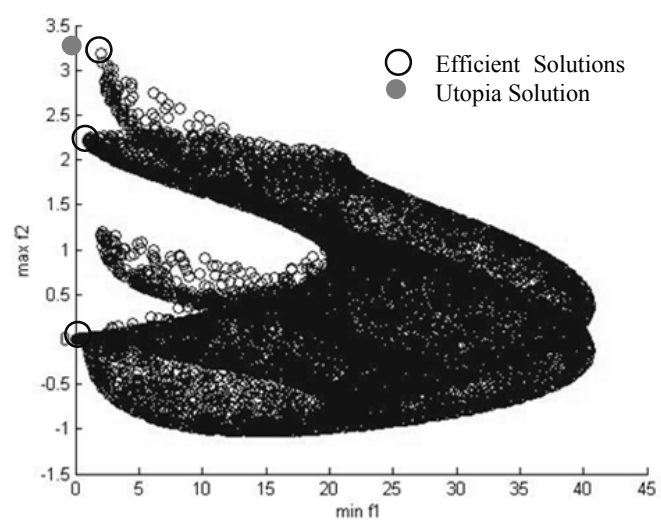

Table 1:Individual optimal solutions

\begin{tabular}{|c|c|c|}
\hline Function & Optimal Solution(s) & Optimal Value \\
\hline$f_{1}$ & $(0,0)$ & 0.00 \\
\hline$f_{2}$ & $(-1,-1),(1,1)$ & 3.23 \\
\hline
\end{tabular}

Table 2: Real efficient solutions

\begin{tabular}{ccc}
\hline$\left(\boldsymbol{x}_{\mathbf{1}}, \boldsymbol{x}_{\mathbf{2}}\right)$ & $\boldsymbol{f}_{\boldsymbol{1}}(\mathbf{x})(\boldsymbol{m i n})$ & $\boldsymbol{f}_{\mathbf{2}}(\mathbf{x})(\mathbf{m a x})$ \\
\hline$(0,0)$ & 0.00 & 0.00 \\
$(-1,0)$ & 1.00 & 2.23 \\
$(1,0)$ & 1.00 & 2.23 \\
$(-1,-1)$ & 2.00 & 3.23 \\
$(1,1)$ & 2.00 & 3.23 \\
\hline
\end{tabular}

Figure 2: Values of $f_{1}$ and $f_{2}$ for 10,000 random inputs

The optimization problem for this illustrative example is mathematically defined as follows:

$$
\begin{array}{lc}
\text { Find } & \mathbf{x}=\left(x_{1}, x_{2}\right) \text { to } \\
\text { Minimize } & f_{l}(\mathbf{x}) \text { and } \\
\text { Maximize } & f_{2}(\mathbf{x}) \\
\text { Subject to } & -1 \leq x_{i} \leq 1 \text { for } i=1,2
\end{array}
$$

In order to solve problem (1), the described multicriteria optimization via simulation method was applied. Two different initial design of experiments were used: a Central Composite Design (CCD) and a Latin Hypercube Design (LHD). The metamodels used in both cases are saturated multi-linear regression models, that is, if $n$ points were simulated, a regression model with $n-1$ parameters is estimated using the method of least squares. Terms are added to the model in a chronological order.

\subsection{Case 1: Optimization using a Central Composite Design}

Referring to Figure 1 the methodology is as follows:

\section{Initialization}

i. Initial DOE: The method begins with a Central Composite Design with 9 runs (a single center run). The values of the controllable variables ( $x_{1}$ and $x_{2}$ in this case) as well as the values of both performance measures are graphically shown in Figures 3 and 4 respectively. 


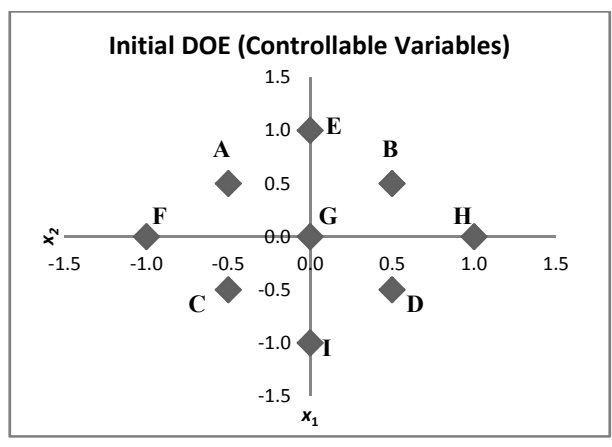

Figure 3: Initial DOE

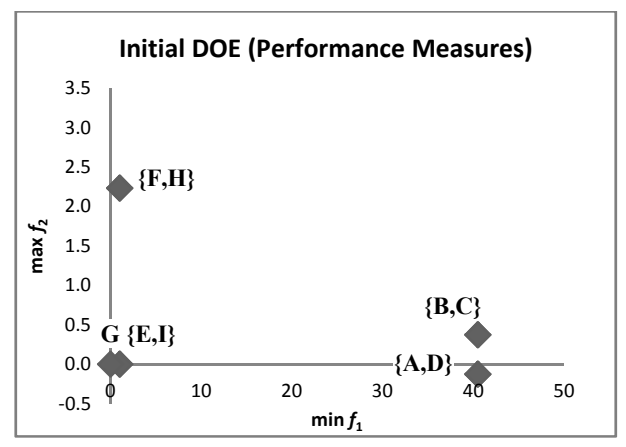

Figure 4: Evaluation of initial DOE

ii. Select incumbent efficient frontier: First an iteration counter is initialized, $k:=0$. Considering the optimization criteria detailed in formulation (1), the non-dominated solutions are found via DEA. These solutions are set as the current incumbent efficient frontier $\left(\boldsymbol{P}_{k \text {-best }}\right), \boldsymbol{P}_{0 \text {-best }}=\{\mathrm{G},\{\mathrm{F}, \mathrm{H}\}\}$.

\section{Main Iteration 1}

1. Update iteration counter: $k=k+1=1$

2. Obtain metamodels: Using the available points, build the $k$-th metamodel for each of the $M$ PMs, $\widehat{f_{m}}(\cdot)_{k},(m=1,2, \ldots, M), M=2$ in this case. The proposed metamodels are multi-linear regression models of the highest possible order. Equations (2) and (3) show the resultant metamodels, the corresponding coefficients of determination $\left(R^{2}\right)$ are $18.8 \%$ and $95.6 \%$. Notice that to avoid dimensionality effects the values of $f_{l}(\mathbf{x})$ and $f_{2}(\mathbf{x})$ were transformed to fall in the scale -1 to 1 .

$$
\begin{aligned}
& \widehat{f}_{1}(\boldsymbol{x})_{1}=35.56+0.00 x_{1}+0.00 x_{2}-25.67 x_{1}{ }^{2}-25.67 x_{2}{ }^{2}+0.00 x_{1} x_{2}+0.00 x_{1}{ }^{3}+0.00 x_{2}{ }^{3} \\
& \widehat{f}_{2}(\boldsymbol{x})_{1}=-0.39+0.00 x_{1}+0.00 x_{2}+2.52 x_{1}{ }^{2}+0.29 x_{2}{ }^{2}+1.00 x_{1} x_{2}+0.00 x_{1}{ }^{3}+0.00 x_{2}{ }^{3}
\end{aligned}
$$

3. Optimization: Using the metamodel of each performance measure, a set of solutions are randomly generated. Then, DEA is applied to find the efficient frontier (set of efficient solutions) of the generated points, called here predicted efficient frontier $\left(\hat{P}_{k-b e s t}\right)$. Figure 5 shows the generated solutions and the predicted efficient solutions $\left(\hat{P}_{1-b e s t}\right)$.

4. Simulate the new points: Estimate, using the simulation software (in this case using the test functions), the values of $f_{\mathrm{m}}(\cdot)$ for each point on the efficient frontier found on $3\left(\hat{P}_{1-\text { best }}\right)$. Figure 6 shows the evaluation of these solutions along with the solutions of the initial DOE.

5. Update the incumbent efficient frontier: Using the current incumbent efficient solutions $\left(\boldsymbol{P}_{(k-1) \text {-best }}=\boldsymbol{P}_{0-}\right.$ best $)$ and the new simulated solutions (step 4$)$, update the incumbent efficient frontier $\left(\boldsymbol{P}_{k \text {-best }}:=\boldsymbol{P}_{1 \text {-best }}\right)$, that is, find the efficient solutions among these. Figure 7 shows the new efficient frontier $\left(\boldsymbol{P}_{1 \text {-best }}\right)$ and the previous $\left(\boldsymbol{P}_{0 \text {-best }}\right)$.

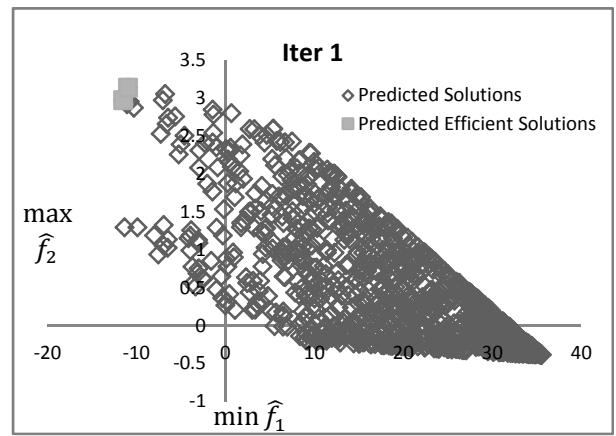

Figure 5: Iteration 1, predicted solutions (diamonds) and efficient solutions (solid squares) 
Villarreal-Marroquín, Cabrera-Ríos, and Castro

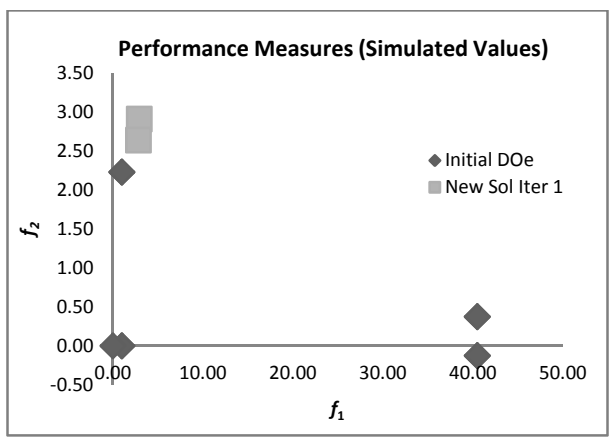

Figure 6: Simulated value of predicted efficient solutions (squares)

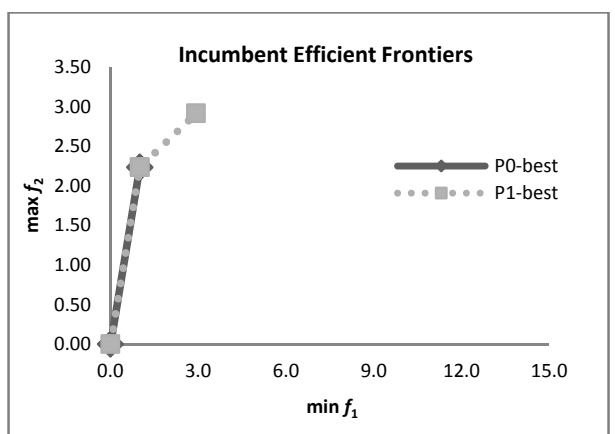

Figure 7: Comparison of incumbent efficient frontier 1 (squares) and 0 (diamonds)

6. Evaluate stopping criteria: The following stopping criteria were considered: stop if (1) the incumbent efficient frontier does not change (no new efficient solutions are added) through a determined number of iterations; (2) if the coefficient of determination $\mathrm{R}^{2} \geq 1-\varepsilon$ ( $\varepsilon$ is a small number, smaller than 1$)$ for all the metamodels; (3) a maximum number of simulation evaluations has been reached. For illustration purposes we assume that none of the stopping conditions was met.

Because none of the stopping criteria were met, the simulated solutions (squared points in Figure 6) are added to the set of available points to build a new metamodel for each PM, and the main iteration is repeated.

\section{Iteration $k:=2$}

After constructing the new metamodels, a new set of random solutions is generated, and the values of the performance measures are estimated using these metamodels $\left(\widehat{f}_{1}(\boldsymbol{x})_{2}\right.$ and $\left.\widehat{f}_{2}(\boldsymbol{x})_{2}\right)$. The new metamodels include an additional regression coefficient per added solution to the set of existing points. Via DEA the predicted efficient frontier $\left(\hat{P}_{2-b e s t}\right)$ is obtained. The predicted efficient solutions are then simulated and compared with the last incumbent efficient solutions $\left(\boldsymbol{P}_{\text {l-best }}\right)$. Figure 8 shows the change of the incumbent efficient frontier after 4 iterations. The algorithm was stopped because the $\mathrm{R}^{2}$ of both metamodels exited the set value $(\varepsilon=0.05)$, the $\mathrm{R}^{2}$ of $f_{1}(\mathbf{x})_{4}$ equaled $99.1 \%$ and the $\mathrm{R}^{2}$ of $f_{2}(\mathbf{x})_{4}$ equaled $100 \%$. The final efficient frontier consists of 4 solutions which are shown in Table 3.

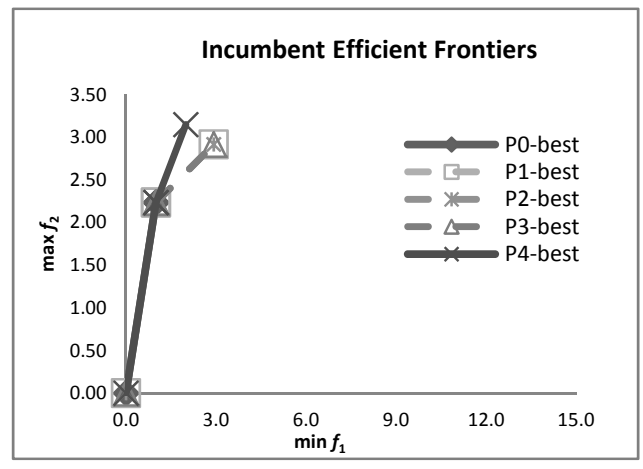

Table 3: Final Efficient Solutions Case 1

\begin{tabular}{cccc}
\hline $\mathbf{x}_{\mathbf{1}}$ & $\mathbf{x}_{\mathbf{2}}$ & $\mathbf{f}_{\mathbf{1}}$ & $\mathbf{f}_{\mathbf{2}}$ \\
\hline 0.0000 & 0.0000 & 0.0000 & 0.0000 \\
-1.0000 & 0.0000 & 1.0000 & 2.2333 \\
1.0000 & 0.0000 & 1.0000 & 2.2333 \\
-0.9956 & -0.9916 & 1.9922 & 3.1477 \\
\hline
\end{tabular}

Figure 8: Change of incumbent efficient frontier

\subsection{Case 2: Optimization using a Latin Hypercube Design}

The optimization process was repeated starting with a space filling Latin Hypercube Design. The LHD consists of 9 points (same number of points that the CCD) which are shown in Figure 9. Figure 10 shows the values of the performance measures $\left(f_{1}\right.$ and $\left.f_{2}\right)$ at each design point. 


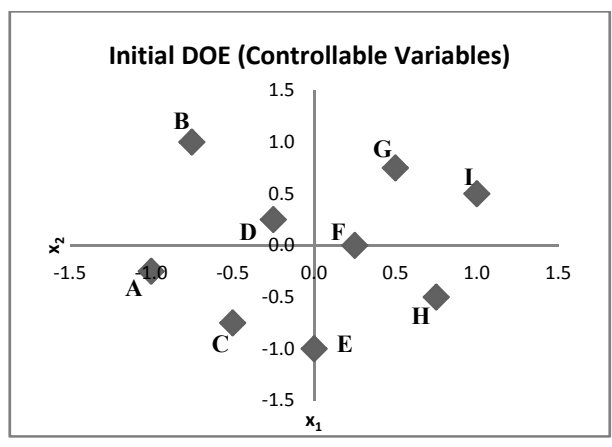

Figure 9: Initial DOE (LHD)

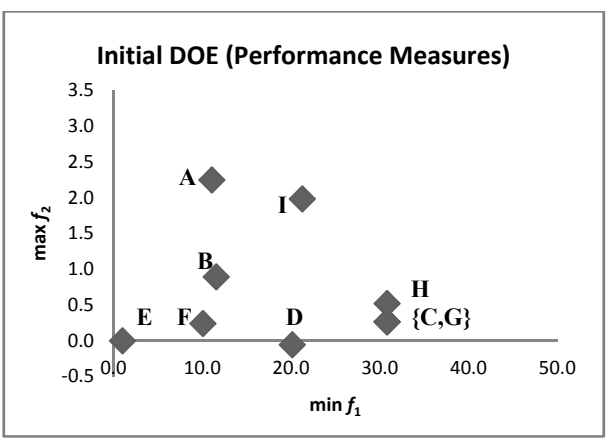

Figure 10: Evaluation of initial DOE

The optimization proceeded as in the previous case (Section 3.1). Figure 11 shows the incumbent efficient frontier at each iteration of the method. The method stopped at iteration 3 because the $\mathrm{R}^{2}$ of both metamodels was $100 \%$. The final efficient solutions are shown in Table 4.

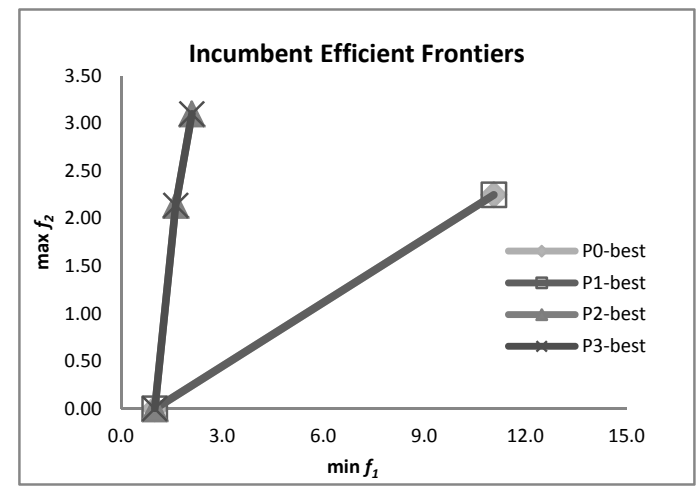

Table 4: Final Efficient Solutions Case 2

\begin{tabular}{cccc}
\hline \multicolumn{1}{c}{$\mathbf{x}_{\mathbf{1}}$} & $\mathbf{x}_{\mathbf{2}}$ & $\mathbf{f}_{\mathbf{1}}$ & $\mathbf{f}_{\mathbf{2}}$ \\
\hline 0.0000 & -1.0000 & 1.0000 & 0.0000 \\
0.9829 & -0.0552 & 1.6219 & 2.1385 \\
-0.9713 & -0.9936 & 2.1010 & 3.0993 \\
\hline
\end{tabular}

Figure 11: Incumbent Efficient Frontiers

A comparison of the real efficient solutions and the efficient solutions found by the optimization algorithm on both cases is given in Figure 12, the actual values are given in Tables 2 to 4 . As we can see when we run the optimization algorithm using a CCD as initial DOE, the method was able to find almost all the real efficient solutions ( 3 are equal and one is very close). On the other hand, when using a LHD the method identified closely only one solution. Therefore, the initial DOE plays an important role on the course of the optimization. Regarding the total number of simulations required by the method, both cases used the same number of simulations, 18 .

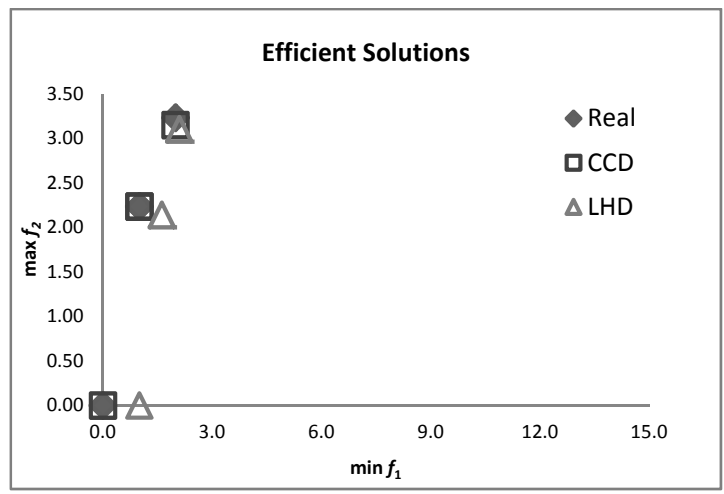

Figure 12: Comparison of efficient solutions found by the optimization method vs. real efficient solutions. 
While space filling designs, such as the LHD used here, are commonly used on the analysis of deterministic computer experiments (Simpson et al. 2001), we believe CCDs do also a good job in combination with regression models for the optimization of deterministic simulation models. In the future we will analyze the performance of both DOEs in combination with Gaussian models. The goal is to have a precise idea of which combination of experimental design and metamodel works best to identify the efficient solutions of multicriteria injection molding problems with the minimum number of simulation runs.

Next section presents the optimization of a real injection molding part.

\section{INJECTION MOLDING APPLICATION}

To further illustrate the application of the proposed methodology, we analyze the molding of a disposable camera. Two scenarios are discussed, the first one involves two performance measures and the second one, three. In both cases we ran the optimization method using two initial DOEs, a CCD and a LHD. Two controllable variables are used in all cases.

Here, it is desirable that the molded part preserves the designed symmetry and dimensions. The part to be analyzed is the front plate of the camera shown in Figure 13.

We assume it is desired to keep the shape of the biggest rectangular window (upper right corner) after shrinkage. The performance measure of interest is the difference between the diagonal's shrinkage $\left(\mid \Delta \mathrm{a}_{3}-\right.$ $\left.\Delta \mathrm{b}_{3} \mid\right)$. For the purposes of the example, we will also assume that it is desired to minimize the shrinkages of the diagonals $a_{3}$ and $b_{3}\left(\Delta a_{3}, \Delta b_{3}\right)$, see Figure 14 for a better representation. As mentioned above, two cases are analyzed, the first one focuses only on the minimization of $\Delta \mathrm{a}_{3}$ and $\left|\Delta \mathrm{a}_{3}-\Delta \mathrm{b}_{3}\right|$; and the second case on the minimization of the three performance measures $\left(\left|\Delta \mathrm{a}_{3}\right|,\left|\Delta \mathrm{b}_{3}\right|\right.$ and $\left.\left|\Delta \mathrm{a}_{3}-\Delta \mathrm{b}_{3}\right|\right)$.

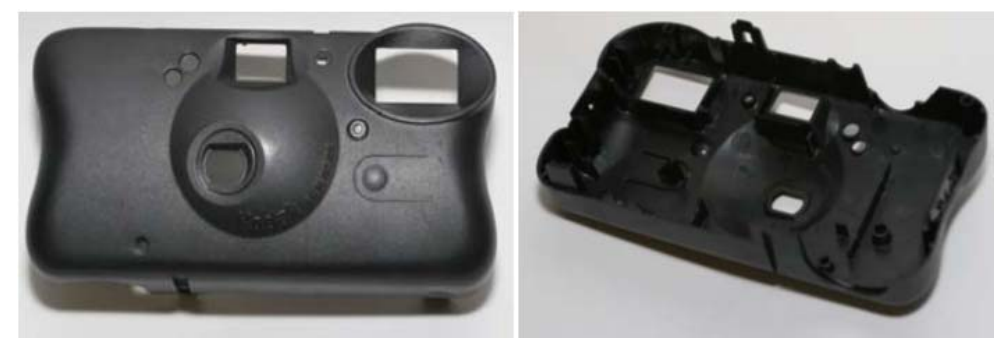

Figure 13: Disposable camera under study

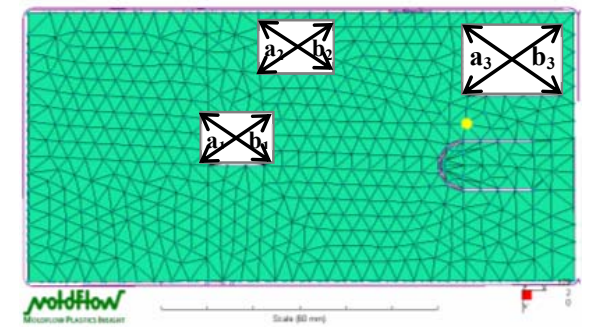

Figure 14: Mesh of disposable camera

The camera studied here is simulated to be injection molded using Poly-Styrene made by Dow Chemical USA (trade name Styron 685D). Packing pressure and melt temperature were held constant at 50 $\mathrm{MPa}$ and $200^{\circ} \mathrm{C}$ respectively. The fill time was kept constant at $1 \mathrm{~s}$; and the cooling time was set automatically. An automatic cooling time is the time required to achieve a target average mold temperature (set here at $108{ }^{\circ} \mathrm{C}$ ) and the specified percentage of the part that needs to be frozen (set here at $100 \%$ ). Mold temperature $\left(\mathrm{T}_{\text {mold }}\right)$ and packing time $\left(\mathrm{t}_{\text {pack }}\right)$ were considered as controllable variables and are varied in the ranges of $[20,70]^{\circ} \mathrm{C}$ and $[1,10] \mathrm{s}$ respectively. MoldFlow ${ }^{\mathrm{TM}}$ is the simulation software used to analyze this process.

The optimization problems for this application are mathematically defined as follows:

Find $\quad \mathrm{T}_{\text {mold }}, \mathrm{t}_{\text {pack }}$ to

Minimize $\quad f_{l}(\mathbf{x}):=\left|\Delta \mathrm{a}_{3}\right|$ and $f_{2}(\mathbf{x}):=\left|\Delta \mathrm{a}_{3}-\Delta \mathrm{b}_{3}\right|$

Subject to $20^{\circ} \mathrm{C} \leq \mathrm{T}_{\text {mold }} \leq 70^{\circ} \mathrm{C}$ $1 \mathrm{~s} \leq \mathrm{t}_{\text {pack }} \leq 10 \mathrm{~s}$
Find $\quad \mathrm{T}_{\text {mold }}, \mathrm{t}_{\text {pack }}$ to

Minimize $\quad f_{l}(\mathbf{x}):=\left|\Delta \mathrm{a}_{3}\right|, f_{2}(\mathbf{x}):=\left|\Delta \mathrm{b}_{3}\right|$ and

$$
f_{3}(\mathbf{x}):=\left|\Delta \mathrm{a}_{3}-\Delta \mathrm{b}_{3}\right|
$$

Subject to $\quad 20^{\circ} \mathrm{C} \leq \mathrm{T}_{\text {mold }} \leq 70^{\circ} \mathrm{C}$

$1 \mathrm{~s} \leq \mathrm{t}_{\text {pack }} \leq 10 \mathrm{~s}$

In optimization problems (4) and (5), the values of shrinkage $\left(\Delta \mathrm{a}_{3}\right)$ and $\left(\Delta \mathrm{b}_{3}\right)$ are estimated via MoldFlow $^{\mathrm{TM}}$. The constraints represent the experimental region of the controllable variables: mold temperature and packing time. 


\subsection{Case 1: Optimization Problem with two performance measures (4)}

To solve problem (4), the proposed multicriteria optimization via simulation method was applied. Two initial DOEs were used, a Central Composite Design shown in Figure 15 and a Latin Hypercube Design shown in Figure 16. The evaluation of both performance measures $\left(f_{l}(\mathbf{x}):=\left|\Delta \mathrm{a}_{3}\right|\right.$ and $\left.f_{2}(\mathbf{x}):=\left|\Delta \mathrm{a}_{3}-\Delta \mathrm{b}_{3}\right|\right)$ at each design point are graphically shown in Figures 17 and 18.

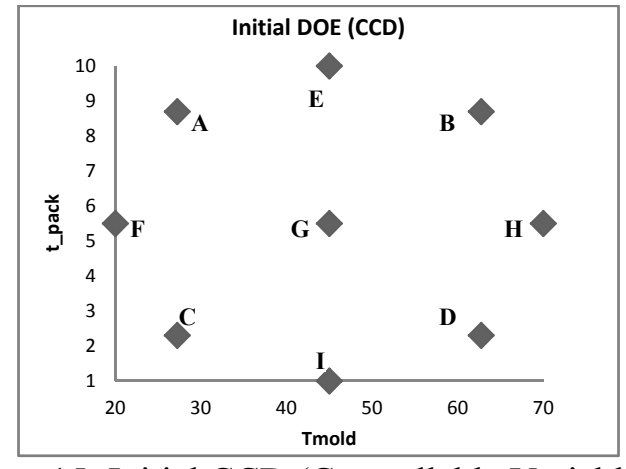

Figure 15: Initial CCD (Controllable Variables)

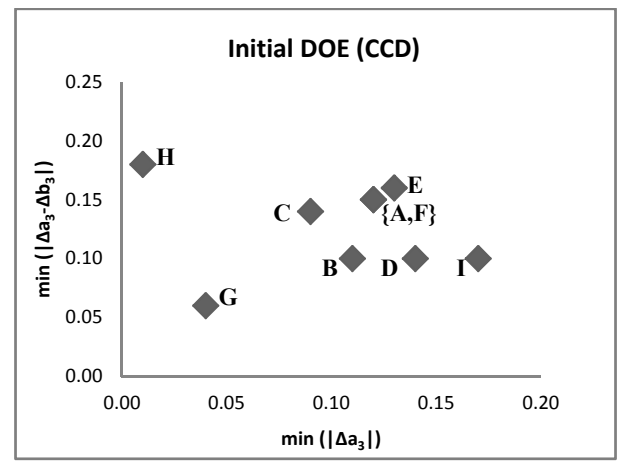

Figure 17: PM values of CCD runs

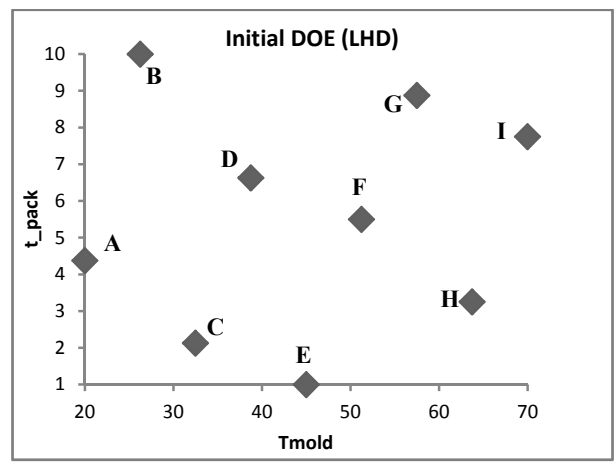

Figure 16: Initial LHD (Controllable Variables)

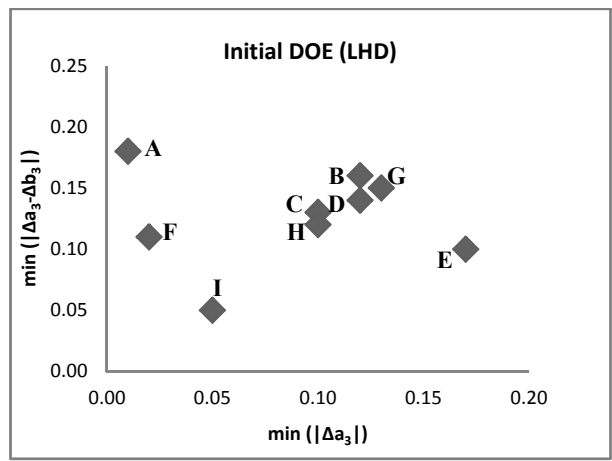

Figure 18: PM values of LHD runs

Figures 19 and 20 show the incumbent efficient frontier at each iteration of the optimization algorithm when starting with the CCD and the LHD respectively. In both cases saturated multi-linear regression models, as the ones used on Section 3, were used as metamodels. Data Envelopment Analysis was used to find the efficient solutions. A comparison of the final efficient frontiers is presented in Figure 21. In Figure 21 we can see that the final solution of the algorithm is improved when the algorithm is started with the CCD than with the LHD. Tables 5 shows the values of the final efficient solutions.

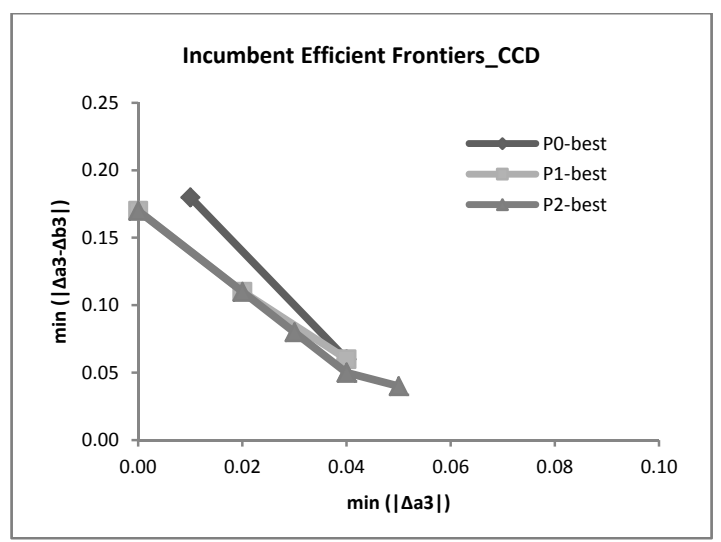

Figure 19: Incumbent Efficient Frontiers using CCD Figure 20: Incumbent Efficient Frontiers using LHD

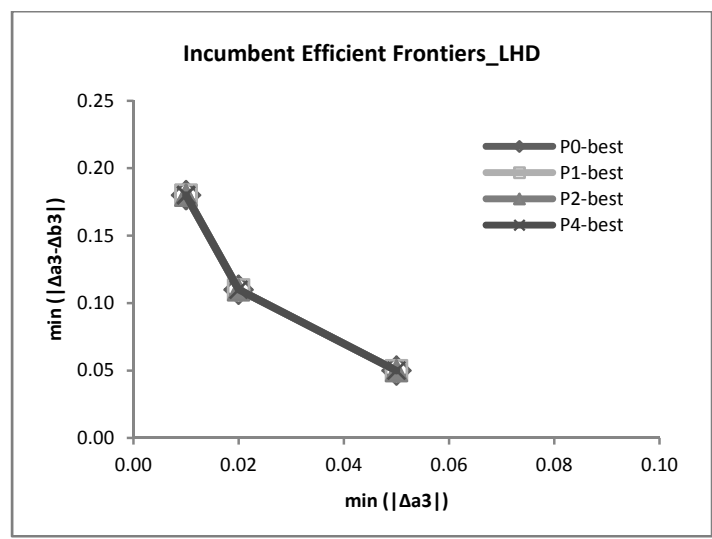




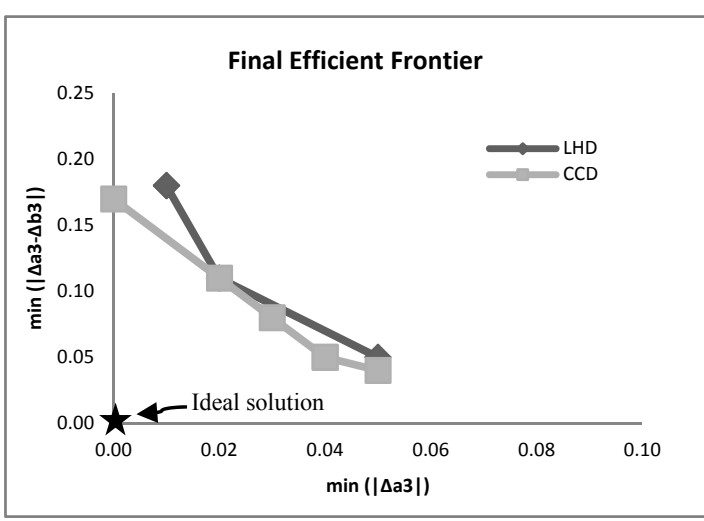

Figure 21: Comparison of final efficient frontiers
Table 5: Final Efficient Solutions

\begin{tabular}{ccccc}
\hline $\begin{array}{c}\text { Initial } \\
\text { DOE }\end{array}$ & $\begin{array}{c}\mathbf{t}_{\text {pack }} \\
(\mathbf{s})\end{array}$ & $\begin{array}{c}\mathbf{T}_{\text {mold }} \\
\left({ }^{\mathbf{0}} \mathbf{C}\right)\end{array}$ & $\begin{array}{c}|\Delta \mathbf{a 3}| \\
(\mathbf{m m})\end{array}$ & $\begin{array}{c}|\Delta \mathbf{a 3}-\Delta \mathbf{b 3}| \\
(\mathbf{m m})\end{array}$ \\
\hline CCD & 5 & 45 & 0.00 & 0.17 \\
CCD & 6 & 51 & 0.02 & 0.11 \\
CCD & 6 & 46 & 0.03 & 0.08 \\
CCD & 6 & 40 & 0.04 & 0.05 \\
CCD & 6 & 41 & 0.04 & 0.05 \\
CCD & 6 & 39 & 0.05 & 0.04 \\
\hline LHD & 4 & 20 & 0.01 & 0.18 \\
LHD & 6 & 70 & 0.01 & 0.18 \\
LHD & 6 & 51 & 0.02 & 0.11 \\
LHD & 8 & 70 & 0.05 & 0.05 \\
\hline
\end{tabular}

\subsection{Case 2: Optimization Problem with Three performance measures (5)}

In order to optimize problem (5) we ran the optimization algorithm with the same DOEs as in problem (4) (see Figures 15 and 16 as reference). Figure 22 shows the evaluation of the PMs at each design point. Figures $23 \mathrm{a}$ and $23 \mathrm{~b}$ show the incumbent efficient frontier at each iteration of the algorithm, when a CCD and a LHD were used. Figure 24 shows the final efficient solutions of both cases. Table 6 gives the values of the final efficient solutions. Once again the final efficient solutions when using a CCD outperformed the ones obtained when using an LHD. Regarding the number of simulations, the algorithm required 33 runs when started with the CCD and 37 runs with the LHD. In this case each simulation run takes 70 seconds + setup time. Simulations of bigger and more complex parts can take hours or days to evaluate a single run.

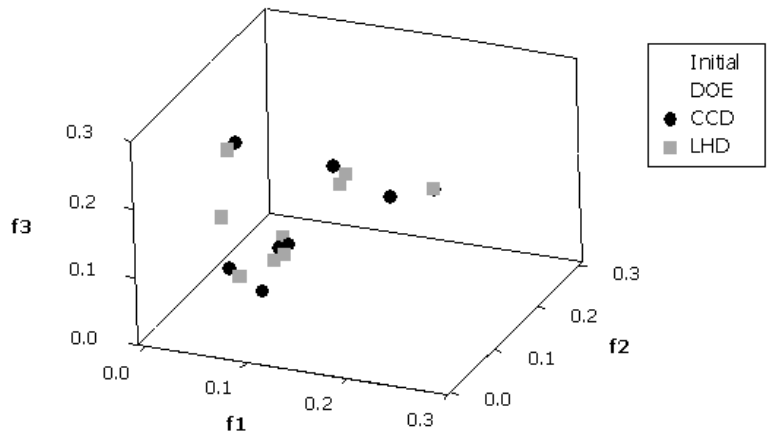

Figure 22: Evaluation of initial design of experiments, CCD (circles) and LHD (squares).

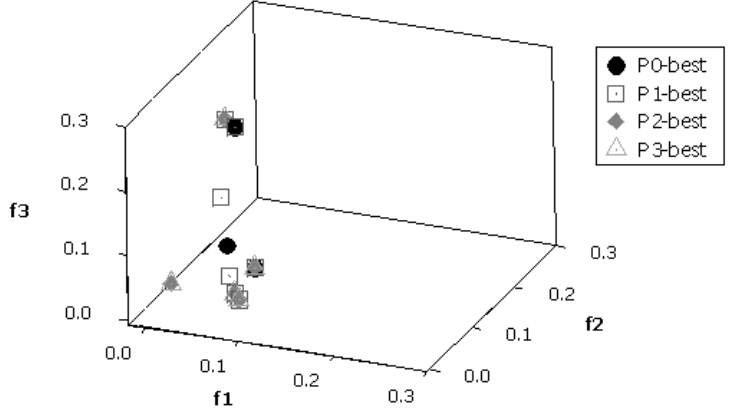

(a) Initial DOE: CCD

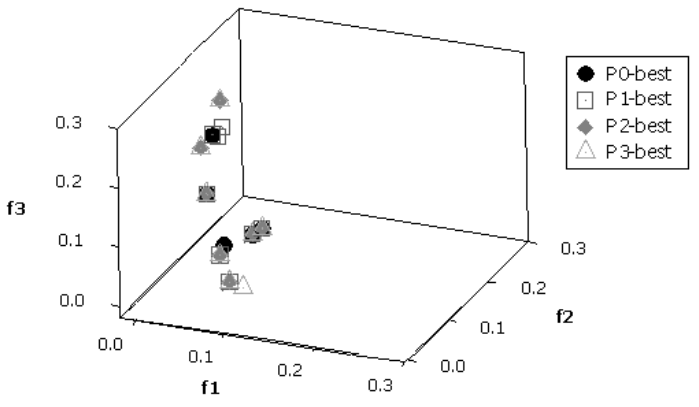

(b) Initial DOE: LHD

Figure 23: Change of Incumbent Efficient Frontier 


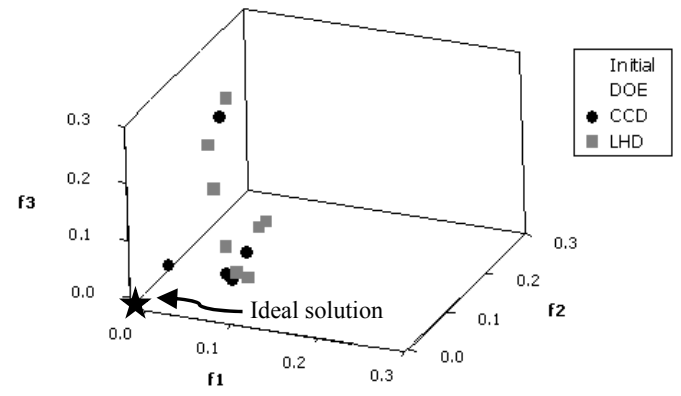

Figure 24: Final efficient solutions

Table 6: Efficient solutions

\begin{tabular}{cccccccccccc}
\hline $\begin{array}{c}\text { Initial } \\
\text { Design }\end{array}$ & $\begin{array}{c}\mathbf{T}_{\text {mold }} \\
\left({ }^{\circ} \mathbf{C}\right)\end{array}$ & $\begin{array}{c}\mathbf{t}_{\text {pack }} \\
(\mathbf{s})\end{array}$ & $\begin{array}{c}|\Delta \mathbf{a 3}| \\
(\mathbf{m m})\end{array}$ & $\begin{array}{c}|\Delta \mathbf{b 3}| \\
(\mathbf{m m})\end{array}$ & $\begin{array}{c}|\Delta \mathbf{a 3}-\Delta \mathbf{b 3}| \\
(\mathbf{m m})\end{array}$ & $\begin{array}{c}\text { Initial } \\
\text { Design }\end{array}$ & $\begin{array}{c}\mathbf{T}_{\text {mold }} \\
\left({ }^{\left.{ }^{\circ} \mathbf{C}\right)}\right.\end{array}$ & $\begin{array}{c}\mathbf{t}_{\text {pack }} \\
(\mathbf{s})\end{array}$ & $\begin{array}{c}|\Delta \mathbf{a 3}| \\
(\mathbf{m m})\end{array}$ & $\begin{array}{c}|\Delta \mathbf{b 3}| \\
(\mathbf{m m})\end{array}$ & $\begin{array}{c}|\Delta \mathbf{a 3}-\Delta \mathbf{b 3}| \\
(\mathbf{m m})\end{array}$ \\
\hline CCD & 45.0 & 4.6 & 0.00 & 0.19 & 0.19 & LHD & 70.0 & 8.2 & 0.05 & 0.09 & 0.04 \\
CCD & 25.0 & 6.4 & 0.01 & 0.03 & 0.04 & LHD & 70.0 & 9.1 & 0.08 & 0.05 & 0.03 \\
CCD & 40.0 & 6.4 & 0.06 & 0.07 & 0.01 & LHD & 70.0 & 4.6 & 0.08 & 0.08 & 0.00 \\
CCD & 50.0 & 7.3 & 0.07 & 0.06 & 0.01 & LHD & 38.8 & 6.6 & 0.12 & 0.02 & 0.14 \\
CCD & 62.8 & 8.7 & 0.11 & 0.01 & 0.10 & LHD & 60.0 & 10.0 & 0.13 & 0.02 & 0.15 \\
\hline LHD & 30.0 & 4.6 & 0.00 & 0.16 & 0.16 & LHD & 65.0 & 10.0 & 0.13 & 0.02 & 0.15 \\
LHD & 35.0 & 3.7 & 0.00 & 0.21 & 0.21 & LHD & 70.0 & 10.0 & 0.13 & 0.02 & 0.15 \\
LHD & 51.3 & 5.5 & 0.02 & 0.13 & 0.11 & LHD & 57.5 & 8.9 & 0.13 & 0.02 & 0.15 \\
\hline
\end{tabular}

From the set of efficient solutions the decision maker can select the best alternative depending on the particular application.

\section{CONCLUSIONS AND FUTURE WORK}

This paper introduced an optimization via simulation methodology for multicriteria problems. The methodology combines design of experiments and metamodeling techniques to reduce the number of simulation evaluations. This makes it attractive for cases where simulations take long time to run, like the ones used to analyze the injection molding process.

An example using global optimization test functions was used to illustrate the methodology. To observe how the final efficient frontier is affected by the selection of the initial design of experiments, two different initial DOEs were evaluated, a CCD and a LHD. An application to injection molding is also presented. Two variations of this case were presented; one involving 2 PMs and a one with 3 PM. Two different initial DOEs were also applied in these cases. In all the cases DEA was used to find the efficient solutions.

Our group is in the process of comparing the results with actual experiments as well as investigating the use of different metamodeling techniques. In addition, we are evaluating how to map the efficient frontier into process windows, which can be used by engineers to better interpret the efficient solutions.

\section{REFERENCES}

Alam, K., and M. R. Kamal. 2005. "A Robust Optimization of Injection Molding Runner Balancing." Computer Applications in Chemical Engineering 29(9):1934-1944. 
April, J., M. Better, F. Glover, and J. Kelly. 2004. "New Advances and Applications for Marrying Simulation and Optimization." In Proceedings of the 2004 Winter Simulation Conference, edited by R .G. Ingalls, M. D. Rossetti, J. S. Smith, and B. A. Peters, 80-86. Piscataway, New Jersey: Institute of Electrical and Electronics Engineers, Inc.

Azadivar F. 1999. "Simulation Optimization Methodologies." In Proceedings of the 1999 Winter Simulation Conference, edited by P. A. Farrington, H. B. Nembhard, D. T. Sturrock, and G. W. Evans, 93100. Piscataway, New Jersey: Institute of Electrical and Electronics Engineers, Inc.

Cabrera-Ríos, M., J. M. Castro, and C. A. Mount-Campbell. 2002. "Multiple Quality Criteria Optimization in In-Mold Coating (IMC) with a Data Envelopment Analysis Approach." Journal of Polymer Engineering 22(5):305-340.

Cabrera-Ríos, M., K. S. Zuyev, X. Chen, J. M. Castro, and E. J. Straus. 2002. "Optimizing Injection Gate Location and Cycle Time for the In-Mold Coating (IMC) Process." Polymer Composites 23(5):723738.

Castro, C. E., M. Cabrera-Ríos, B. Lilly and J. M. Castro. 2005. "Simultaneous Optimization of Mold Design and Processing Conditions in Injection Molding." Journal of Polymer Engineering 25(6):459486.

Castro, C. E., M. Cabrera-Ríos, B. Lilly, and J.M. Castro. 2007. "Optimization and Analysis of Variability in Injection Molding." Journal of Polymer Engineering and Science 47(4):400-409.

Charnes, A., W. W. Cooper, A. Y. Lewin, and L. M. Seiford. 1993. Data Envelopment Analysis: Theory, Methodology, and Applications. Boston: Kluwer Academic Publishers.

Dellino, G., and J. P. C. Kleijnen. 2009. "Robust Simulation-Optimization Using Metamodels." In Proceedings of the 2009 Winter Simulation, Conference, edited by M. D. Rossetti, R. R. Hill, B. Johansson, A. Dunkin and R. G. Ingalls, 540-550. Piscataway, New Jersey: Institute of Electrical and Electronics Engineers, Inc.

Fu, M. C. 2001. "Simulation Optimization." In Proceedings of the 2001 Winter Simulation Conference, edited by B. A. Peters, J. S. Smith, D. J. Medeiros, and M. W. Rohrer, 53-61. Piscataway, New Jersey: Institute of Electrical and Electronics Engineers, Inc.

Fu, M. C., F. Glover, and J. April. 2005. "Simulation Optimization: A Review, New Developments, and Application." In Proceedings of the 2005 Winter Simulation Conference, edited by M. E. Kuhl, N. M. Steiger, F. B. Armstrong, and J. A. Joines, 83-95. Piscataway, New Jersey: Institute of Electrical and Electronics Engineers, Inc.

Ólafsson, S., and J. Kim. 2002. "Simulation Optimization." In Proceedings of the 2002 Winter Simulation Conference, edited by E. Yücesan, C.-H. Chen, J. L. Snowdon, and J. M. Charnes, 79-84. Piscataway, New Jersey: Institute of Electrical and Electronics Engineers, Inc.

Ryu, J.-H., S. Kim, and H. Wan. 2009. "Pareto Front Approximation with Adaptive Weighted Sum Method in Multiobjective Simulation Optimization." In Proceedings of the 2009 Winter Simulation Conference, edited by M. D. Rossetti, R. R. Hill, B. Johansson, A. Dunkin and R. G. Ingalls, 623633. Piscataway, New Jersey: Institute of Electrical and Electronics Engineers, Inc.

Simpson, T. W., J. D. Poplinski, P. N. Koch, and J. K. Allen. 2001. "Metamodels for Computer-based Engineering Design: Survey and recommendations." Engineering with Computers 17(12):129-150.

Smith, D. E., D. A. Tortorelli, and C. L. Tucker. 1998. "Analysis and Sensitivity Analysis for Polymer Injection and Compression Molding." Computer Methods in Applied Mechanics and Engineering 167(3/4):325-344.

Swisher, J. R., P. D. Hyden, S. H. Jacobson, and L. E. Schruben. 2000. "A survey of simulation optimization techniques and procedures." In Proceedings of the 2000 Winter Simulation Conference, edited by J. A. Joines, R. R. Barton, K. Kang, and P. A. Fishwick, 119-128. Piscataway, New Jersey: Institute of Electrical and Electronics Engineers, Inc.

Villarreal, M. G., M. Mulyana, J. M. Castro, and M. Cabrera-Ríos. 2008. "Simulation Optimization Applied to Injection Molding." In Proceedings of the 2008 Winter Simulation Conference, edited by S. J. 
Mason, R. R. Hill, L. Mönch, O. Rose, T. Jefferson, J. W. Fowler, 1995-2003. Piscataway, New Jersey: Institute of Electrical and Electronics Engineers, Inc.

Zakerifar, M., W. E. Biles, and G. V. Evens. 2009. "Kriging Metamodeling in Multi-Objective Simulation Optimization." In Proceedings of the 2009 Winter Simulation Conference, edited by M. D. Rossetti, R. R. Hill, B. Johansson, A. Dunkin and R. G. Ingalls, 2115-2122. Piscataway, New Jersey: Institute of Electrical and Electronics Engineers, Inc.

Zhou, J., and L. S. Turng. 2007. "Process Optimization of Injection Molding Using an Adaptive Surrogate Model with Gaussian Process Approach." Polymer Engineering and Science 47(5):684-694.

\section{AUTHOR BIOGRAPHIES}

MARÍA G. VILLARREAL-MARROQUíN is a PhD candidate in Industrial \& Systems Engineering at The Ohio State University. She obtained her B.S. in Mathematics (2005) and M.S. in Systems Engineering (2007) from Universidad Autónoma de Nuevo León, México. Her research interests include Simulation Optimization, and applied optimization in manufacturing. Her e-mail address is villarrealmarroquin.1@osu.edu.

JOSE M CASTRO is currently professor in the Department of Integrated Systems Engineering and Director of the Center for Advanced Polymer and Composite Engineering at The Ohio State University. After obtaining his $\mathrm{PhD}$ in Chemical Engineering from the University of Minnesota in 1980, he was a faculty at the University of the South in Bahia Blanca Argentina for 4 years. He then worked at the Gen Corp corporate technology center for 12 years as chief technologist. After GenCorp he worked for 3 years as Manager of the New Process technology group in Allied Signal Electronic Materials. He joined Ohio State in September 1998. He has published more than 70 peer reviewed journal papers and given numerous invited talks. His area of research is polymer processing and composites manufacturing modeling and optimization. His e-mail address is castro.38@osu.edu.

MAURICIO CABRERA-RIOS is an Assistant Professor in the Industrial Engineering Department at University of Puerto Rico-Mayagüez. He obtained his B.S. degree in Industrial \& Systems Engineering from Monterrey Institute of Technology (ITESM), in Monterrey, México in 1996. He obtained an M.S. and $\mathrm{Ph} . \mathrm{D}$. degrees in the same field from The Ohio State University in 1999 and 2002 respectively. He was an Associate Professor at the Graduate Program in Systems Engineering at UANL, México from 2003 to 2008. Prof. Cabrera-Ríos is a member of INFORMS, IIE and the American Association of Cancer Researchers. His research work currently relates to biological data analysis and to applied optimization in manufacturing. His e-mail address is mauricio.cabrera1@upr.edu. 